\title{
COVID-19 Pandemic: Do Learning Motivation and Learning Self-Efficacy Exist among Higher Vocational College Students?
}

\author{
Shenlong Tang ${ }^{1}$ \\ Siti Zuraidah Md Osman ${ }^{\star}$ (iD) \\ ${ }^{1,2}$ School of Educational Studies, University Sains Malaysia, Pulau Pinang, Malaysia. \\ 'Email: tangshenlong@student.usm.my Tel: +8615666885371 \\ "Email: sitizuraidah@usm.my Tel: +60194745358
}

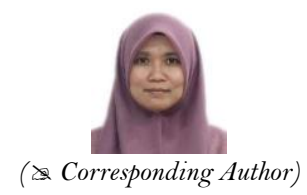

\begin{abstract}
COVID-19 first appeared in the first quarter of 2020 and spread rapidly throughout the world. Now, schools in China have resumed face-to-face teaching on campus, but the COVID-19 Pandemic still impacts normal teaching activities and student psychology. This quantitative research revealed the levels of learning motivation and learning self-efficacy among higher vocational college students. This study also investigated whether these variables vary according to students' gender, hometown, family structure and field of study. In addition, this research examined the relationship between students' learning motivation and learning self-efficacy. The sample for the survey was 1018 students from a public higher vocational college in Shandong Province. The research collected data via two surveys, the Learning Motivation Scale (LMS) designed by Tian and Pan (2006) and the Learning Self-Efficacy Scale (LSS) designed by Liang (2000). The research used percentages, means, standard deviations, independent group t-test and Pearson correlation coefficient to analyze the data. The results revealed that higher vocational college students' learning motivation and learning self-efficacy scores were above the median score of the two scales. The study found that learning motivation did not vary according to students' gender, field of study or family structure. However, students from different hometowns showed a significant difference in their learning self-efficacy but no significant difference in their learning motivation. Finally, the researchers discovered a significant positive correlation between learning motivation and learning self-efficacy.
\end{abstract}

Keywords: Learning motivation, Learning self-efficacy, Higher vocational college students, COVID-19 pandemic.

Citation | Shenlong Tang; Siti Zuraidah Md Osman (2022). COVID-19 Pandemic: Do Learning Motivation and Learning SelfEfficacy Exist among Higher Vocational College Students? Journal of Education and e-Learning Research, 9(1): 38-44. History:

Received: 4 January 2022

Revised: 14 February 2022

Accepted: 28 February 2022

Published: 7 March 2020

Licensed: This work is licensed under a Creative Commons

Attribution 4.0 License (cc) Ey

Publisher: Asian Online Journal Publishing Group
Funding: This study received no specific financial support.

Authors' Contributions: Both authors contributed equally to the conception and design of the study. Competing Interests: The authors declare that they have no conflict of interests.

Transparency: The authors confirm that the manuscript is an honest, accurate, and transparent account of the study; that no vital features of the study have been omitted; and that any discrepancies from the study as planned have been explained.

Ethical: This study followed all ethical practices during writing.

\section{Contents}

1. Introduction

2. Methods ....

3. Results

4. Discussion

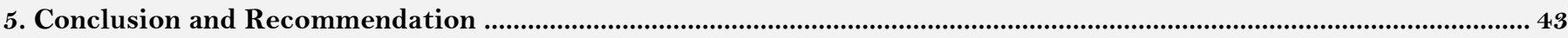

References... 


\section{Contributions of this paper to literature}

This study contributes to existing literature by investigating the levels of learning motivation and learning self-efficacy among higher vocational college students during the COVID-19 Pandemic period.

\section{Introduction}

The spread of the COVID-19 Pandemic has resulted in widespread prevention measures being taken in countries around the world. These control measures have resulted in various changes in lifestyle activities, including school activities, activities at educational institutions and also educational policies (Moawad, 2020; Toquero, 2020). The COVID-19 Pandemic has affected people's mental health to a certain extent. As a sensitive group, students are more vulnerable to the impact of the environment (Jin, Zhang, \& Peng, 2021; Liu, 2020). According to Liu and $\mathrm{Li}$ (2021), college students are in a period of rapid growth in mind and body and they are sensitive to their surroundings. Several studies have revealed an increase in anxiety and stress symptoms among students in reaction to the COVID-19 Pandemic (Alsairafi, Naser, Alsaleh, Awad, \& Jalal, 2021; Campos, Pinto, Alves, Rosa, \& Pereira, 2021; Cao et al., 2020; Chen et al., 2020; Cimen, Alvur, Coşkun, \& Şükür, 2021; Lyons, Wilcox, Leung, \& Dearsley, 2020).

China resumed face-to-face teaching in schools in May 2020. However, under the normalization of COVID-19 prevention and control rules practiced in China, normal teaching activities are sometimes disrupted by the epidemic. At the same time, college students still receive a steady stream of information on international and domestic epidemic situations. These information may have an impact on students' learning psychology (Chen, Xu, \& Lu, 2020; Ding \& Hu, 2020; Liu, 2020). Previous research has shown that the levels of students' learning motivation and learning self-efficacy affect their learning behavior and learning performance (Abdelrahman, 2020; Ahmet, 2019; Chepsiror, 2021; Mupfumira \& Nyaruwata, 2021; Riswanto \& Aryani, 2017; Talsma, Schüz, Schwarzer, \& Norris, 2018; Wang \& Lin, 2021). Educational institutions, especially policymakers need to understand students' learning psychology and provide appropriate interventions. This can help students master knowledge and improve learning outcomes (Xu, Zhang, Qiu, \& Li, 2021). However, current research in China pays less attention to students' learning psychology during the present pandemic, including learning motivation and learning self-efficacy of higher vocational college students. Therefore, this study aims to determine whether the COVID-19 Pandemic has influenced higher vocational students' learning motivation and learning self-efficacy. The research results can provide evidence for teachers, educational institutions and policymakers to understand students' current learning motivation and self-efficacy levels and introduce the necessary intervention measures.

The research questions are as follows:

- What is higher vocational college students' level of learning motivation during the COVID-19 Pandemic?

- What is higher vocational college students' level of learning self-efficacy during the COVID-19 Pandemic?

- Do higher vocational college students' learning motivations differ according to gender, hometown, field of study and family member structure?

- Do higher vocational college students' learning self-efficacy differ according to gender, hometown, field of study and family member structure?

- Is there a relationship between higher vocational college students' learning motivation and learning selfefficacy?

\section{Methods}

\subsection{Research Design}

This research aims to investigate the levels of higher vocational college students' learning motivation and learning self-efficacy during the COVID-19 pandemic and to determine the relationship between these variables and students' gender, hometown, field of study and family member structure. In addition, the research also explores the relationship between higher vocational college students' learning motivation and learning self-efficacy. The researchers have used the survey design (descriptive method) in this study.

\subsection{Sample / Participants}

The participants in this research were 1150 students (17-19 years old) from Shandong vocational college of science and technology. The students volunteered to participate in the survey. Table 1 shows the demography of the sample group.

Table 1. Summary of respondents' demography.

\begin{tabular}{l|c|c|c}
\hline \multirow{2}{*}{ Variables } & Characteristics & $\mathbf{N}$ & $\mathbf{\%}$ \\
\hline \multirow{2}{*}{ Gender } & Male & 346 & 34.1 \\
\hline \multirow{2}{*}{ Hometown } & Female & 672 & 65.9 \\
\cline { 2 - 4 } & Rural area & 853 & 83.8 \\
\cline { 2 - 4 } \multirow{2}{*}{ Field of study } & Urban area & 165 & 16.2 \\
\cline { 2 - 4 } & Humanities and Social Sciences & 655 & 64.3 \\
\cline { 2 - 4 } Family structure & Science and Engineering & 363 & 35.7 \\
\cline { 2 - 4 } & Only child & 208 & 20.4 \\
\hline
\end{tabular}

\subsection{Instrument $(s)$}

The instrument for collecting data on motivation for this study was the Learning Motivation Scale (LMS). The LMS was developed by Tian and Pan (2006) to measure students' learning motivation, and it consists of 34 items used in the 5-point Likert format, with values ranging from $1=$ do not agree at all to $5=$ strongly agree. The original LMS measured 427 students, and the reliability and validity of the scale met the requirements of 
psychometrics. The Cronbach's alpha reliability score for this study is 0.927. Four aspects were considered in the LMS: interest in knowledge (Cronbach's Alpha $=0.818$ ), ability pursuit (Cronbach's Alpha $=0.778$ ), altruism orientation (Cronbach's Alpha $=0.858$ ), and reputation acquisition (Cronbach's Alpha $=0.872$ ). The sample items for the four aspects are as follows:

(1) Interest in knowledge (11 items): I always think that studying at a university is a pleasant experience.

(2) Ability pursuit (8 items): I constantly remind myself to improve my analytical and problem-solving skills throughout the learning process.

(3) Altruism orientation ( 8 items): I am sure the desire to make my country more affluent and more robust in the future is the primary motivation for my studies.

(4) Reputation acquisition ( 7 items): I want to study hard and improve my position in class.

The study's Learning Self-efficacy Scale (LSS) was developed by Liang (2000) with a 5-point Likert format. The scale consists of 22 questions on students' self-efficacy related to behavior learning self-efficacy and ability learning self-efficacy. The scale shows that the two dimensions have acceptable reliability and validity, with Cronbach's alpha values at 0.752 and 0.820 . The Cronbach's alpha reliability score of the learning self-efficacy scale in this study is 0.890 , with the Cronbach's alpha being 0.810 and 0.853 for each dimension. The two dimensions in the LSS are described below, with one sample question for each:

(1) Behavior learning self-efficacy (11 questions): I believe I can get good grades in my studies.

(2) Ability learning self-efficacy (11 questions): I always record important points in books or notebooks to help with my studies.

\subsection{Data Collection and Analysis}

All students volunteered to complete answering all items in the questionnaire in class. In the data collection process, the participants were made to understand the purpose of the study, emphasizing that participation in the survey was voluntary and they were assured that the data was confidential and would not be shared with third parties. Participants had the right to stop answering the questionnaire at any time. It took about 15 minutes to collect all the data. The study received 1150 questionnaires, of which 52 were invalid, and the remaining 1098 valid questionnaires were analyzed, to answer the 5 research questions. Percentages, means, standard deviations, independent group t-test and Pearson correlation coefficient were used to analyze the data.

\begin{tabular}{l|c|c|c|c|c} 
Table 2. Descriptive statistics on learning motivation of higher vocational college students. \\
\hline Dimension & Item & Mean & SD & Min & Max \\
\hline Learning motivation & 34 & 3.42 & 0.60 & 1.30 & 5.00 \\
\hline Interest in knowledge & 11 & 3.59 & 0.64 & 1.00 & 5.00 \\
\hline Ability pursuit & 8 & 3.48 & 0.66 & 1.00 & 5.00 \\
\hline Altruism orientation & 8 & 3.53 & 0.68 & 1.00 & 5.00 \\
\hline Reputation acquisition & 7 & 2.98 & 0.84 & 1.00 & 5.00 \\
\hline
\end{tabular}

\section{Results}

Table 2 shows that the average score of higher vocational college students' learning motivation is 3.42; the lowest is 1.30 , and the highest is 5.00. Data on the sub dimensions show that the mean in interest in knowledge is 3.59; in ability pursuit is 3.48; in altruism orientation is 3.53 and in reputation acquisition is 2.98 . The mean scores of these dimensions are higher than the average score of the total scale, except for reputation acquisition. The minimum and maximum scores for the four dimensions are 1.00 and 5.00.

Table 3. T-test statistics on differences in learning motivation based on students' gender.

\begin{tabular}{|c|c|c|c|c|c|c|}
\hline \multirow{2}{*}{ Dimension } & \multicolumn{2}{|c|}{ Male } & \multicolumn{2}{|c|}{ Female } & \multirow{2}{*}{$\mathbf{t}$} & \multirow{2}{*}{$\mathbf{p}$} \\
\hline & Mean & SD & Mean & SD & & \\
\hline Learning motivation & 3.45 & 0.69 & 3.41 & 0.54 & 0.813 & 0.417 \\
\hline Interest in knowledge & 3.63 & 0.73 & 3.56 & 0.59 & 1.524 & 0.128 \\
\hline Ability pursuit & 3.49 & 0.77 & 3.48 & 0.60 & 0.112 & 0.911 \\
\hline Altruism orientation & 3.47 & 0.77 & 3.56 & 0.62 & -1.770 & 0.077 \\
\hline Reputation acquisition & 3.08 & 0.89 & 2.93 & 0.81 & 2.578 & 0.010 \\
\hline
\end{tabular}

According to Table 3, the mean score in male students' learning motivation (3.45) is higher than that of female students (3.41). In addition to altruism orientation, the mean scores of male students are higher than those of female students in the other three dimensions. Independent sample t-test results show no significant effect of gender difference on learning motivation other than reputation acquisition $(\mathrm{P}<0.05)$.

Table 4. T-test statistics on differences in learning motivation based on students' hometowns.

\begin{tabular}{l|c|c|c|c|c|c}
\hline \multirow{2}{*}{ Dimension } & \multicolumn{2}{|c|}{ Rural areas } & \multicolumn{2}{c|}{ Urban areas } & \multirow{2}{*}{$\mathbf{t}$} & $\mathbf{P}$ \\
\cline { 2 - 6 } & Mean & SD & Mean & SD & t & 0.214 \\
\hline Learning motivation & 3.41 & 0.58 & 3.48 & 0.67 & -1.248 & 0.260 \\
\hline Interest in knowledge & 3.58 & 0.63 & 3.64 & 0.68 & -1.127 & 0.504 \\
\hline Ability pursuit & 3.47 & 0.65 & 3.51 & 0.72 & -0.668 & 0.504 \\
\hline Altruism orientation & 3.52 & 0.66 & 3.58 & 0.77 & -0.973 & 0.331 \\
\hline Reputation acquisition & 2.99 & 0.82 & 3.11 & 0.81 & -2.126 & 0.034 \\
\hline Note: Town =853; City =165.
\end{tabular}

The data in Table 4 shows that in the area of learning motivation, the mean score of students from the rural areas is 3.41 and that of students from the urban areas is 3.48 . The average scores of students in urban areas are 
higher than that of students in rural areas in the four subscales. The Independent groups t-test results show that students in different places have significant differences in reputation acquisition $(\mathrm{P}<0.05)$.

\begin{tabular}{|c|c|c|c|c|c|c|}
\hline \multirow{2}{*}{ Dimension } & \multicolumn{2}{|c|}{ Only child } & \multicolumn{2}{|c|}{ No-only child } & \multirow[t]{2}{*}{$\mathbf{t}$} & \multirow[t]{2}{*}{$\mathbf{p}$} \\
\hline & Mean & SD & Mean & SD & & \\
\hline Learning motivation & 3.47 & 0.66 & 3.41 & 0.58 & 1.259 & 0.209 \\
\hline Interest in knowledge & 3.66 & 0.68 & 3.57 & 0.63 & 1.962 & 0.050 \\
\hline Ability pursuit & 3.50 & 0.73 & 3.47 & 0.64 & 0.509 & 0.611 \\
\hline Altruism orientation & 3.51 & 0.75 & 3.53 & 0.66 & 0.433 & 0.666 \\
\hline Reputation acquisition & 3.10 & 0.86 & 2.95 & 0.83 & 2.259 & 0.064 \\
\hline
\end{tabular}

As seen in Table 5, the mean score in learning motivation of only child students is 3.47 , and that of non-only child students is 3.41 . The average score of non-only child students is higher than only child students only in altruistic orientation. An independent group t-test was used to examine whether there was a significant difference between students' learning motivation and family structure. According to t-test results, the family structure did not affect learning motivation $(\mathrm{p}>0.05)$.

\begin{tabular}{|c|c|c|c|c|c|c|}
\hline \multirow[t]{2}{*}{ Dimension } & \multicolumn{2}{|c|}{ Science and Engineering } & \multicolumn{2}{|c|}{$\begin{array}{l}\text { Humanities and } \\
\text { Social Sciences }\end{array}$} & \multirow[t]{2}{*}{$\mathbf{T}$} & \multirow[t]{2}{*}{$\mathbf{P}$} \\
\hline & Mean & SD & Mean & SD & & \\
\hline Learning motivation & 3.4 & 0.6 & 3.44 & 0.6 & -0.991 & 0.322 \\
\hline Interest in knowledge & 3.57 & 0.65 & 3.6 & 0.64 & -0.647 & 0.518 \\
\hline Ability pursuit & 3.45 & 0.67 & 3.5 & 0.65 & -1.111 & 0.267 \\
\hline Altruism orientation & 3.48 & 0.68 & 3.56 & 0.67 & -1.952 & 0.051 \\
\hline Reputation acquisition & 2.98 & 0.81 & 2.99 & 0.86 & -0.096 & 0.924 \\
\hline
\end{tabular}

As seen in Table 6, the average learning motivation score of humanities and social sciences students is 3.44, while that of science and engineering students is 3.40. The mean scores of students under humanities and social sciences are higher than that of students who study science and engineering, in four aspects. The data in the t-test demonstrated that there was no significant difference in learning motivation among students in different fields of study.

Table 7. Descriptive statistics on learning self-efficacy of higher vocational college students.

\begin{tabular}{l|c|c|c|c|c}
\hline Dimension & Item & Mean & SD & Min & Max \\
\hline Learning self-efficacy & 22 & 3.43 & 0.51 & 1.64 & 5.00 \\
\hline Behavior learning self-efficacy & 11 & 3.33 & 0.50 & 1.36 & 5.00 \\
\hline Ability learning self-efficacy & 11 & 3.53 & 0.60 & 1.00 & 5.00 \\
\hline
\end{tabular}

As presented in Table 7, the average score of higher vocational college students in learning self-efficacy is 3.43; the lowest score is 1.64 and the highest score is 5.00. The mean score of behavior learning self-efficacy is 3.33, lower than the average score of the total scale. However, the mean score of ability learning self-efficacy is higher than the overall average score. The maximum score of the two sub dimensions is 5.00 while the minimum scores are 1.36 and 1.00 .

Table 8. T-test statistics on differences in learning self-efficacy based on students' gender.

\begin{tabular}{|c|c|c|c|c|c|c|}
\hline \multirow{2}{*}{ Dimension } & \multicolumn{2}{|c|}{ Male } & \multicolumn{2}{|c|}{ Female } & \multirow{2}{*}{$\mathbf{t}$} & \multirow[b]{2}{*}{$\mathbf{p}$} \\
\hline & Mean & SD & Mean & SD & & \\
\hline Learning self-efficacy & 3.46 & 0.57 & 3.42 & 0.48 & 1.008 & 0.314 \\
\hline Behavior learning self-efficacy & 3.32 & 0.55 & 3.33 & 0.47 & -0.316 & 0.752 \\
\hline Ability learning self-efficacy & 3.59 & 0.67 & 3.50 & 0.55 & 2.003 & 0.046 \\
\hline
\end{tabular}

Note: Male $=346$; Female $=672$.

Table 8 indicates that the mean score of learning self-efficacy for male students is 3.46 , and that of female students is 3.42. The average score of male students in behavioral learning self-efficacy is 3.32, which is lower than that of female students (3.33). The reverse is seen in the aspect of ability learning self-efficacy. The t-test data shows a significant difference in ability learning self-efficacy based on students' gender $(\mathrm{p}<0.05)$.

Table 9. T-test statistics of differences in learning self-efficacy based on students' hometown.

\begin{tabular}{l|c|c|c|c|c|c}
\multicolumn{2}{c}{ Table 9. T-test statistics of differences in learning self-efficacy based on students' hometown. } \\
\hline \multirow{2}{*}{ Dimension } & \multicolumn{2}{|c|}{ Rural area } & \multicolumn{2}{c|}{ Urban area } & \multirow{2}{*}{ P } \\
\cline { 2 - 6 } & Mean & SD & Mean & SD & & \\
\hline Learning self-efficacy & 3.40 & 0.50 & 3.55 & 0.57 & -3.331 & 0.001 \\
\hline Behavior learning self-efficacy & 3.31 & 0.49 & 3.43 & 0.51 & -2.893 & 0.004 \\
\hline Ability learning self-efficacy & 3.50 & 0.57 & 3.67 & 0.70 & -2.898 & 0.004 \\
\hline Note: Town =853; City =165.
\end{tabular}

As seen in Table 9, the average self-efficacy score of students in the urban areas (3.55) is higher than that of students in the rural areas (3.40). The mean score of students from the rural areas is lower than the urban group in behavioral learning self-efficacy, and it is the same in the mean score of ability learning self-efficacy. The t-test results show a significant difference in all scales of students from different places $(\mathrm{P}<0.05)$. 
Table 10. T-test statistics of differences in learning self-efficacy based on students' family structures.

\begin{tabular}{|c|c|c|c|c|c|c|}
\hline \multirow{2}{*}{ Dimension } & \multicolumn{2}{|c|}{ Only child } & \multicolumn{2}{|c|}{ Non-only child } & \multirow[t]{2}{*}{$\mathrm{t}$} & \multirow[t]{2}{*}{$\bar{p}$} \\
\hline & Mean & SD & Mean & SD & & \\
\hline Learning self-efficacy & 3.48 & 0.56 & 3.42 & 0.50 & 1.755 & 0.080 \\
\hline Behavior learning self-efficacy & 3.78 & 0.53 & 3.32 & 0.50 & 1.611 & 0.108 \\
\hline Ability learning self-efficacy & 3.59 & 0.66 & 3.51 & 0.58 & 1.688 & 0.092 \\
\hline
\end{tabular}

Note: Only child =208; Non-only child $=810$.

Table 10 shows the mean score in learning self-efficacy of students who are the only child is 3.48 , and that of students who are not the only child is 3.42. The average scores of the two types of students' behavior learning selfefficacy are 3.78 and 3.32, respectively. In addition, the average score of ability learning self-efficacy of only child students is also higher than that of non-only child students. Independent group t-test statistics confirm that students' mean scores in all aspects show no significant differences based on family structure.

Table 11. T-test statistics on differences in learning self-efficacy based on students' fields of study.

\begin{tabular}{|c|c|c|c|c|c|c|}
\hline \multirow[t]{2}{*}{ Dimension } & \multicolumn{2}{|c|}{ Science and Engineering } & \multicolumn{2}{|c|}{$\begin{array}{l}\text { Humanities and } \\
\text { Social Sciences }\end{array}$} & \multirow[t]{2}{*}{$\mathbf{t}$} & \multirow[t]{2}{*}{$\mathbf{P}$} \\
\hline & Mean & SD & Mean & SD & & \\
\hline Learning self-efficacy & 3.42 & 0.49 & 3.44 & 0.52 & -0.517 & 0.606 \\
\hline Behavior learning self-efficacy & 3.30 & 0.47 & 3.34 & 0.51 & -1.259 & 0.258 \\
\hline Ability learning self-efficacy & 3.53 & 0.59 & 3.54 & 0.60 & 0.164 & 0.870 \\
\hline
\end{tabular}

Note: Science and Engineering $=363$; Humanities and Social Sciences $=655$.

As shown in Table 11, the average learning self-efficacy score of students majoring in humanities and social sciences is 3.44, while that of students majoring in science and engineering is 3.42. Students who study humanities and social sciences have a higher mean score compared with students who study science and engineering in both sub dimensions. No significant difference is found between students' fields of study on all scales in the independent group t-test.

Table 12. Relationship between learning motivation and learning self-efficacy of students.

\begin{tabular}{c|c|c|c|c|c|c|c|c}
\multicolumn{7}{c}{ Table 12. Relationship between learning motivation and learning self-efficacy of students. } \\
\hline Dimension & IIK & AP & AR & RA & LM & BLSE & ALSE & LSE \\
\hline IIK & 1 & & & & & & & \\
\hline AP & $0.783^{* *}$ & 1 & & & & & & \\
\hline AR & $0.681^{* *}$ & $0.764^{* *}$ & 1 & & & & & \\
\hline RA & $0.429^{* *}$ & $0.612^{* *}$ & 0.662 & 1 & & & & \\
\hline LM & $0.858^{* *}$ & $0.913^{* *}$ & 0.894 & $0.773^{* *}$ & 1 & & & \\
\hline BLSE & $0.606^{* *}$ & $0.573^{* *}$ & $0.599^{* *}$ & $0.390^{* *}$ & $0.630^{* *}$ & 1 & & \\
\hline ALSE & $0.621^{* *}$ & $0.607^{* *}$ & $0.667^{* *}$ & $0.495^{* *}$ & $0.694^{* *}$ & $0.746^{* *}$ & 1 & \\
\hline LSE & $0.657^{* *}$ & $0.633^{* *}$ & $0.680^{* *}$ & $0.479^{* *}$ & $0.712^{* *}$ & $0.922^{* *}$ & $0.946^{* *}$ & 1 \\
\hline
\end{tabular}

Note: **a $<0.01$ ( (1\% level of significance).
LSE: learning selfferficacy; BLSE: Behavior learning self-efficacy; ALSE: Ability learning self-efficacy; LM: Learning motivation; IIK: Interest in knowledge; AP

There is a significant positive correlation between learning motivation and learning self-efficacy among higher vocational college students, as shown in Table 12. There is also a positive correlation between all the sub dimensions.

\section{Discussion}

The current study indicates that the learning motivation scores of the higher vocational college students are above the median. The findings of this research are consistent with the findings of studies carried out by Fang (2013); Li (2019); Zhang (2017); Zhang and Li (2019); Tian and Hu (2018); He, Zhu, and Zhu (2015) and Gao (2021). The scores of each dimension of learning motivation range from high to low as follows: interest in knowledge, ability pursuit, altruistic orientation and reputation acquisition. The results of studies conducted by Zhang (2017) support the present findings. However, in the study by Li (2019) and Fang (2013), it was found that the dimension with the highest score was ability pursuit.

Based on gender, male students in this study have a higher mean score compared with female students. The data obtained by Kang (2018); Pang (2015) and Zhao (2015) are parallel with the current findings. A corresponding study by Ahmet (2019) showed different results where the mean score of women was higher than that of men Ahmet (2019). The data from the independent sample t-test revealed that there is no significant gender difference in learning motivation. There are many studies in favor of this finding (Ding \& Wang, 2010; Li \& He, 2011; Su, 2015). However, the present research results are inconsistent with the results of Chi and Xi (2006).In Chi and X's study, the average score of students from the city was higher than that of students from the town. It was found that there was no significant difference in learning motivation based on students' hometowns. Fang (2013) reached the same conclusion. However, it differs from the results of He et al. (2015) and Zhang (2017).

The results of the present study show that the mean score of students (who study humanities and social sciences) in learning motivation is higher than that of students who study science and engineering. Ding (2013) contradicts this result. According to data derived from Ding (2013) study, students' learning motivation did not differ significantly based on their fields of study. A study conducted by $\mathrm{Li}$ and $\mathrm{He}$ (2011) found that there were significant differences in shallow and deep motivation but no significant differences existed in achievement motivation based on students' fields of study. However, the study by Ding and Wang (2010) revealed that there were significant differences in students' deep motivation.

The present study concludes that the learning motivation of the only child students was higher than that of the non-only child students, and the variable of family member structure did not have a significant effect on learning motivation. According to Kang (2018) and Gao (2021), only child students' learning motivation was 
higher than that of non-only child students, and there were no significant differences in this variable. Pang (2015) and Zhao (2015) also determined that no significant differences existed in the variable of family member structure, but non-only child students had higher learning motivation.

The present study results indicate that students' learning self-efficacy levels are above the median. Some studies favor the present findings (Liu, 2021; Zhao, 2015; Zhu, Mu, \& Xu, 2018). Their mean score of ability learning self-efficacy is higher than behavior learning self-efficacy. Previous research have yielded comparable results (Gao, 2021; Kong, 2019; Wang, 2015; Zhao, Wang, Zhu, \& Xue, 2020). Their data results indicated that there was a significant difference based on students' gender variable, with male students having a higher mean learning self-efficacy score compared with female students. A study conducted by Zhao and Mao (2008) showed that there was no significant difference in learning self-efficacy between male and female college students in a corresponding study by Gao (2021), the same results were obtained. However, according to Peng (2017), it was observed that the differences in learning self-efficacy between male and female students were statistically significant.

The present study indicates that students' learning self-efficacy differs significantly in terms of their hometown variable, and students in the city have scored higher than students in town. According to Gao (2021), there were significant differences in learning self-efficacy based on students' hometowns, and the self-efficacy of urban students was higher than that of rural students. In contrast, Li, He, and Sun (2020) had different findings, whereby students' hometown locations s had no significant impact on college students' learning efficacy. Studies by Kong (2019) and Peng (2017) also support this result.

In this study, no significant difference is found between students' fields of study in the area of learning selfefficacy. As cited by Zhao and Mao (2008) there was no statistically significant difference based on students' fields of study. In the present study, the mean score of students in humanities and social sciences was higher than that of science and engineering students. In the study conducted by Li et al. (2020), it was observed that the learning selfefficacy of science and engineering students was higher than that of students in the field of humanities and social sciences.

In the current study, the mean score of only child students in learning self-efficacy was higher than that of non-only child students. The difference in family member structure was statistically significant. Related literature (Liu (2021) and Gao (2021)) reveal the same findings. However, according to Li et al. (2020), whether a student was an only child or otherwise had no significant effect on learning self-efficacy.

As can be seen from the present study, the correlation between higher vocational college students' learning motivation and learning self-efficacy was significant and positive. According to Gao (2021) and Xu, Zhou, and Li (2018), learning self-efficacy has a high positive correlation with learning motivation, and the higher the selfefficacy, the stronger the learning motivation of college students.

\section{Conclusion and Recommendations}

Several studies have revealed an increase in levels of nervousness, anxiety, stress and panic among students in reaction to the COVID-19 Pandemic (Lyons et al., 2020). However, the results of the present study reveal that the levels of learning motivation and learning self-efficacy among higher vocational college students are equal to levels shown in earlier studies. Gender, hometown, field of study and family structure did not change the results significantly compared with previous studies. In other words, the COVID-19 epidemic did not affect students' learning motivation or learning self-efficacy. However, there is still a lot to know about the impact of the covid-19 Pandemic on the learning psychology of Chinese college students. Therefore, more extensive quantitative and qualitative research should be carried out to better understand students' learning psychology and introduce appropriate intervention on time.

\section{References}

Abdelrahman, R. M. (2020). Metacognitive awareness and academic motivation and their impact on academic achievement of Ajman University students. Heliyon, 6(9), e04192.Available at: https://doi.org/10.1016/j.heliyon.2020.e04192.

Ahmet, S. H. (2019). The relationship between academic motivation and academic achievement of the students. Asian Journal of Education and Training, 5(2), 309-315.Available at: https://doi.org/10.20448/journal.522.2019.52.309.315.

Alsairafi, Z., Naser, A., Alsaleh, F. M., Awad, A., \& Jalal, Z. (2021). Mental health status of healthcare professionals and students of health sciences faculties in Kuwait during the COVID-19 pandemic. International Journal of Environmental Research and Public Health, 18(4), 1-15.Available at: https://doi.org/10.3390/ijerph18042203.

Campos, R., Pinto, V., Alves, D., Rosa, C. P., \& Pereira, H. (2021). Impact of COVID-19 on the mental health of medical dtudents in Portugal. Journal of Personalized Medicine, 11(10), 1-14.Available at: https://doi.org/10.3390/jpm 11100986.

Cao, W., Fang, Z., Hou, G., Han, M., Xu, X., Dong, J., \& Zheng, J. (2020). The psychological impact of the COVID-19 epidemic on college students in China. Psychiatry Research, 287, 112934.Available at: https://doi.org/10.1016/j.psychres.2020.1 1293.

Chen, R.-N., Liang, S.-W., Peng, Y., Li, X.-G., Chen, J.-B., Tang, S.-Y., \& Zhao, J.-B. (2020). Mental health status and change in living rhythms among college students in China during the COVID-19 pandemic: A large-scale survey. Journal of Psychosomatic Research, 137, 1102 19.Available at: https://doi.org/10.1016/j.jpsychores.2020.110.

Chen, G., Xu, J. D., \& Lu, J. (2020). Anxiety and associated factors among medical students returned to school during COVID-19 epidemic situation. Chinese Journal of School Health, 41(12), 1851-1855.Available at: https://doi.org/10.16835/j.cnki.1000-9817.2020.12.022.

Chepsiror, P. (2021). Basic tenets of experiential learning in emergent reading activities in early childhood development and education Centres in Kenya: A comparison of public and private schools. International Journal of Social Sciences Perspectives, 8(1), 8-16.Available at: https://doi.org/10.33094/7.2017.2021.81.8.16.

Chi, L. P., \& Xi, Z. Q. (2006). Measurement of College Students' learning motivation and its relationship with self-efficacy. Psychological Development and Education, 2, 64-70.

Cimen, İ. D., Alvur, T. M., Coşkun, B., \& Şükür, N. E. Ö. (2021). Mental health of Turkish medical students during the COVID-19 pandemic. International Journal of Social Psychiatry, 0020764021 1066734.Available at: https://doi.org/10.1177/00207640211066734.

Ding, H. Y., \& Wang, J. Q. (2010). Research on the current situation of college students' learning motivation. Jiangxi Qingnian Zhiye Xueyuan Xuebao, 1, 6-8.

Ding, Y. (2013). An investigation of college students. Learning Motivation Journal of Anhui University of Technology (Social Science), 30(6), 150151.

Ding, M. J., \& Hu, C. F. (2020). Study on the influence of the epidemic situation of COVID-19 on the psychological behavior of college students. Journal of Jiangsu Ocean University (Humanities and Social Sciences Edition), 18(2), 129-140.Available at: https://doi.org/10.3969/j.issn.2096-8256.2020.02.016. 
Fang, S. H. (2013). Investigation and analysis on learning motivation of college students in agricultural colleges. Education and Vocation, 15, $177-179$.

Gao, G. M. (2021). The research on the relationship between learning motivation and self-efficacy of local college students—-taking W University as an example. Journal of Xingtai Polytechnic College, 38(1), 32-38.

He, Z. H., Zhu, J. B., \& Zhu, S. T. (2015). An investigation on the learning motivation of college students in private universities in Guangzhou -- a case study of a private university in Guangdong. Science \& Technology Information, 17, $219-220$

Jin, Z. Y., Zhang, B., \& Peng, W. B. (2021). Investigation on the psychological state of college students and exploration of the psychological assistance work of college instructors during the prevention and control of the COVID-19. Journal of Yunnan Agricultural University (Social Science), 15(1), 127 - 133.Available at: https://doi.org/10.3969/j.issn.1004-390X(s).202009047.

Kang, Y. T. (2018). A study on the relationship between College Students' learning motivation, learning self-efficacy and learning burnout. Taiyuan, China: Shanxi University of Finance and Economics.

Kong, W. H. (2019). A study on the mediating role of College Students' learning self-efficacy in the relationship between professional identity and learning burnout. Shanghai, China: Shanghai Normal University.

Li, J. X., \& He, J. (2011). Study on the degree and characteristics of College Students' learning motivation at different stages. China Journal of Health Psychology, 9, 1904-1905.

Li, L. (2019). Investigation on learning motivation of medical college students. Journal of Henan Medical College, 31(4), 540-541.

Li, X. H., He, P. L., \& Sun, M. (2020). Investigation and research on academic self-efficacy of counterpart college students. Journal of Lv liang University, $10(4), 91-93$.

Liang, Y. S. (2000). A study on College Students' achievement goals, attribution styles and learning self-efficacy. Wuhan, China: Central China Normal University.

Liu, D. (2020). Investigation and countermeasure research on the mental health status of higher vocational students under the COVID-19 Pandemic-Taking 553 students of a higher vocational college as an example. Psy, 15(17), 51-55.Available at: https://doi.org/10.19738/j.cnki.psy.2020.17.016.

Liu, Y. T., \& Li, W. F. (2021). The investigation and analysis on mental health of the student of cruise crew major in post epidemic eratake qingdao ocean shipping mariners college as an example. Qingdao Yuan Yang Chuan Yuan Zhi Ye Xue Yuan Xue Bao, 42(1), 6568.

Liu, L. (2021). Investigation on professional commitment, academic self-efficacy and learning engagement of higher vocational nursing students. The Guide of Science \& Education, 22, 22-25.

Lyons, Z., Wilcox, H., Leung, L., \& Dearsley, O. (2020). COVID-19 and the mental well-being of Australian medical students: Impact, concerns and coping strategies used. Australasian Psychiatry, 28(6), 649-652.Available at: https://doi.org/10.1177/1039856220947945.

Moawad, R. A. (2020). Online learning during the COVID-19 pandemic and academic stress in university students. Romanian Journal for Multidimensional Education, 12 (1 Sup2), 100-107.Available at: https://doi.org/10.18662/ $\mathrm{rrem} / 12.1 \mathrm{sup} 2 / 252$.

Mupfumira, I. M., \& Nyaruwata, L. T. (2021). Challenges in the teaching and learning of textiles in the primary school curriculum in Masvingo District Zimbabwe. Asian Journal of Contemporary Education, 5(1), 12-22.Available at: https://doi.org/10.18488/journal.137.2021.51.12.22.

Pang, J. (2015). Study on the relationship between Higher Vocational Students' learning motivation, psychological capital and academic burnout. Changsha, China: Hunan Normal University.

Peng, C. (2017). A survey of academic self-efficacy of higher vocational colleges students—a case study of Jiangsu Animal Husbandry \& Veterinary College. Journal of Jincheng Institute of Technology, 1O(6), 61-64.

Riswanto, A., \& Aryani, S. (2017). Learning motivation and student achievement: Description analysis and relationships both. COUNS-EDU: The International Journal of Counseling and Education, 2(1), 42-47.Available at: https://doi.org/10.23916/002017026010.

$\mathrm{Su}$, R. C. (2015). Gender and grade differences in college students' learning motivation. Human Resource Management, 12, $191-193$.

Talsma, K., Schüz, B., Schwarzer, R., \& Norris, K. (2018). I believe, therefore I achieve (and vice versa): A meta-analytic cross-lagged panel analysis of self-efficacy and academic performance. Learning and Individual Differences, 61, 136-150.Available at: https://doi.org/10.1016/j.lindif.2017.11.015.

Tian, L., \& Pan, W. G. (2006). Preliminary compilation of the learning motivation scale for college students. Science of Social Psychology, 21(6), $42-46$.

Tian, L., \& Hu, W. (2018). Investigation on learning motivation of Normal College Students: A case study of Hubei Normal University. Contemporary Teacher Education, 3(2), 74-77.

Toquero, C. M. (2020). Challenges and opportunities for higher education amid the COVID-19 pandemic: The Philippine context. Pedagogical Research, 5(4), em0063.Available at: https://doi.org/10.29333/pr/7947.

Wang, B. H. (2015). A study on the relationship between College Students' academic self-efficacy, professional commitment and learning burnout. Harbin, China: Heilongjiang University.

Wang, D., \& Lin, T. T. (2021). A survey of college students' self-efficacy and learner autonomy. Journal of Wenzhou Medical University, 51(3), $253-255$.

Xu, Q. Q., Zhou, B., \& Li, J. J. (2018). The relationship between College Students' learning motivation and academic self-efficacy. Journal of Brand Research, 5, 267-268.Available at: https://doi.org/10.19373/j.cnki.14-1384/f.2018.05.173.

Xu, H. W., Zhang, J. Y., Qiu, S., \& Li, X. (2021). Research on the correlation between online learning ability and academic self-efficacy of college students under the COVID-19 Pandemic. Health Vocational Education, 39(5), 140-142.

Zhang, L. (2017). Investigation on learning motivation of Normal College Students. Campus Life E Mental Health, 15(2), $107-108$.

Zhang, L., \& Li, C. L. (2019). A study on the relationship between learning motivation and learning burnout of college students. Journal of Jining University, $40(1), 99-101$.

Zhao, C. Y., \& Mao, C. (2008). A survey of College Students' learning self-efficacy. Data of Culture and Education, 9, $192-194$.

Zhao, H. J. (2015). A study on the relationship between College Students' learning burnout and learning motivation: An analysis of the mediating effect of attribution style. Chongqing, China: Southwest University.

Zhao, L., Wang, W. J., Zhu, L., \& Xue, F. (2020). Study on learning engagement and academic self-efficacy of college students. Journal of Mudanjiang Normal University (Social Sciences Edition), 6, $131-137$.

Zhu, L., Mu, L. L., \& Xu, H. S. (2018). Study on the relationship between medical students' learning investment, future time insight and academic self-efficacy. Journal of Kaifeng Institute of Education, 1, 179-180. 